\title{
Auditing for patients
}

\author{
Andrew Foster, Daniel Ratchford, David Taylor
}

Issues related to health care quality are receiving increased public attention in many developed countries. The factors responsible range from concerns about the costs of health services and the extent to which the services actually generate better health to new consumer expectations and changing professionalpatient relationships. In the NHS, recent reforms involving, for example, the introduction of commissioning, clinical audit, and the patient's charter, have given an additional impetus to quality.

Some of the Audit Commission's earlier work in quality of health care was outlined in the previous supplement ${ }^{1}$; this paper describes the commission's subsequent thinking and actions and includes, firstly, a brief explanation of the commission's interest in and contributions to health service improvement; secondly, concepts of "quality" and quality management; thirdly, the issues likely to have a critical influence on further progress towards continuous improvement in the NHS; and, finally, the most appropriate "next steps" towards better quality health care and future plans.

The Audit Commission's health studies

Established by statute in 1982, the Audit Commission's initial responsibilities were to appoint the external auditors for local authorities and to help them to ensure that their services are provided economically, effectively, and efficiently. The commission swiftly established a reputation for rigorous analysis, and in 1990 the NHS and Community Care Act transferred to it an additional responsibility for the statutory external audit function of the health service. The government made clear its desire to see more "value for money" studies in health care, conducted by an agency "independent of the health authorities and of the Health Departments."

The commission's specialist staff research VFM analyses (undertaken within an overall audit designed also to assure standards of financial probity and regularity). They prepare both national reports and detailed audit guides which are used by appointed auditors, many of whom work with the District Audit Service combined with the commission in 1982-3 - to conduct VFM analyses in audited bodies. An explicit provider/purchaser distinction is now being made between the District Audit Service and the commission, which also appoints auditors from the private sector, to reflect broader changes in the public sector. Over 20 nationwide investigations of health topics, ranging from day surgery and nursing to pathology services and the work of family health services authorities and district health authorities have been completed since 1989-90. Those in progress cover topics such as prescribing in general practice, services for people with mental illness, development of community care, information technology in the NHS, and GP fundholding.

Through this work the commission has already contributed significantly to improving health care "quality," as defined, for instance, by Maxwell's six dimensions: effectiveness, user acceptability, efficiency, access, equity, and relevance to community needs. ${ }^{3}$ And further efforts to fulfil its responsibilities have accompanied publication of the commission's consultation paper Minding the Quality ${ }^{4}$ and occasional paper Putting Quality on the Map, ${ }^{5}$ which presented a now widely known model emphasising four main areas of quality (fig 1).

Analysis of the responses to Minding the Quality led to an extensive qualitative survey of developments in quality management in the the NHS during 1993 (combined with additional literature reviews and analyses), the findings of which provide the basis of much of this article.

\section{Concepts of quality}

Quality can be understood in terms of service or product attributes and the managerial and

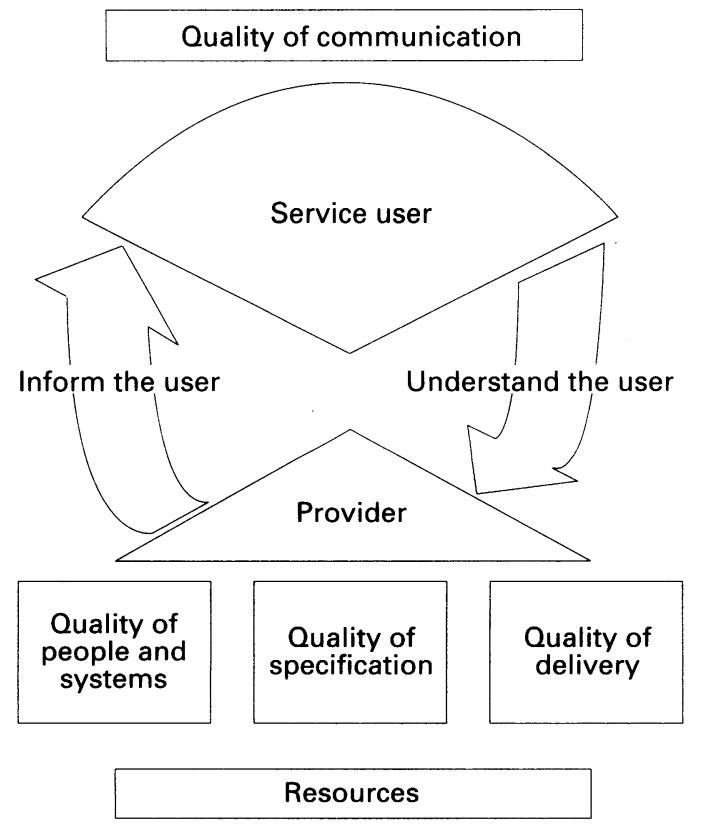

Source: Audit commission ${ }^{5}$

Figure 1 Quality map 


\section{Quality strategies and sectional interests}

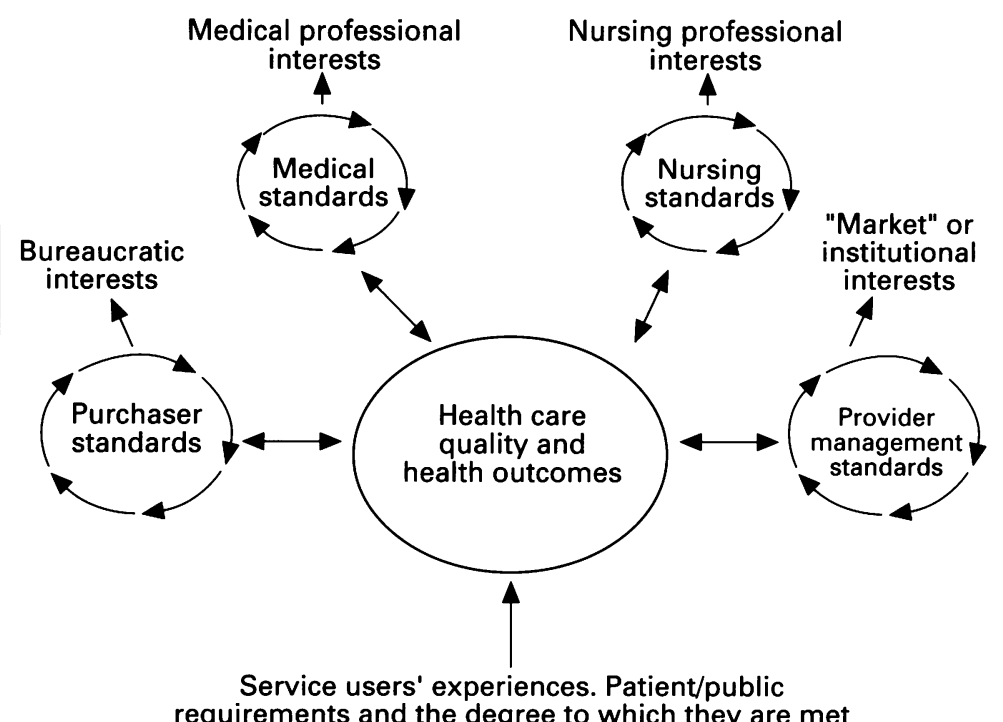

The above model can be linked to the following definitions of quality:

Traditional quality:

Conveying prestige; a "quality" service can be seen as raising self esteem and confidence of users (and its providers).

Scientific and professional Based on "expert" set standards and peer quality: group values. Professionals internalise their collective norms and imperatives, expressing them in terms of their (moral) duties to patients.

Bureaucratic "management" Demands compliance with top-down set rules, quality: impartially applied. Measurements of performance are reliant on indicators approved by the internal hierarchy. Standards set by experts, but ultimately under political control.

Market "management" quality:

Derived from consumer willingness to pay for a service or goods offered in a competitive market place. Cannot without extensive regulatory intervention maximise consumer wellbeing in imperfect market conditions.

"Consumer" quality:
Sometimes confused with market "management" quality. As used here attempts to construct "perfect market" conditions through enhancing purchasing relationships, with consumer involvement in local and national decision making and improved patient participation in treatment processes. Ideally, improved understanding of patient/public requirements will, if communicated effectively, help to draw disparate quality standards together to form a unified "full colour" picture. organisational techniques needed to achieve, and whenever possible improve on, agreed standards. However, some find it a difficult and sometimes unhelpful term, especially in complex areas such as health. Thinking about the interplay between the pursuit of goals like narrowly specified cost efficiency (that is, cheapness) on the one hand and the more subjective aspects of quality on the other can be very confused.

Much of the intellectual underpinning of quality management theories rests on the ideas of market economics. The basic concept of consumer sovereignty is clearly reflected in phrases such as "quality is conformance to (internal and external customer) requirements." But a fundamental problem in relation to health care is that the market conditions for its delivery are inherently imperfect. Consumers commonly lack the knowledge and abilities to judge their own best interests without professional guidance, and third party funding arrangements are often required to transfer resources to those most in need of care. The consequent need for rationing leads to more complex concepts of quality, such as the recommendation that quality in public sector health care should be seen as "the degree to which agreed standards are achieved, and to which those standards are related to the highest priority needs of the users of the service, given existing resource levels and other local restraints." There is good reason to accept this as a working definition of quality of care in the NHS, although it means that differing service user groups may always be in some degree of conflict as to exactly where the boundaries of provision should be drawn.

Ovretveit differentiates between professional quality (the attainment of given clinical and allied care standards), managerial quality (the efficient use of resources within the limits and objectives set by higher management), and client quality (the extent to which end users' satisfaction is achieved). ${ }^{7}$ Pfeffer and Coote distinguish between traditional, scientific, managerial, consumerist, and democratic models of quality. ${ }^{8} \mathrm{~A}$ modified version of their typology, which also complements Ovretveit's approach has been developed at the commission (box). The key point is that, although providers' concerns must, in a quality service, be understood and appreciated, they should never be allowed to obscure or distract attention from users' ultimate best interests.

Internal analysis of quality management theories and concepts as they apply to health care has also led the commission to use the model outlined in figure 2 . The separation this makes between system (whole population); institutional (trust, practice, or other provider agency); and episodic (individual care incident) quality is a simple one, but failure to understand its implications may be a root cause of conflicts between various professional and managerial groups in the NHS.

A final point about concepts of quality in the health service relates to the significance of outcome measurements. The commission supports the recent efforts of many individuals and organisations to emphasise evidence of desired results in work on health service improvement. In the past quality management initiatives seem too often to have been focused on structure and process indicators or standards, regardless of whether or not compliance with them led to better performance as measured in terms of real importance to patients. However, a primary purpose of quality management is to "get things right first time," avoiding tragic or financially costly mistakes. Unwanted events should be "designed out." And in health care, 


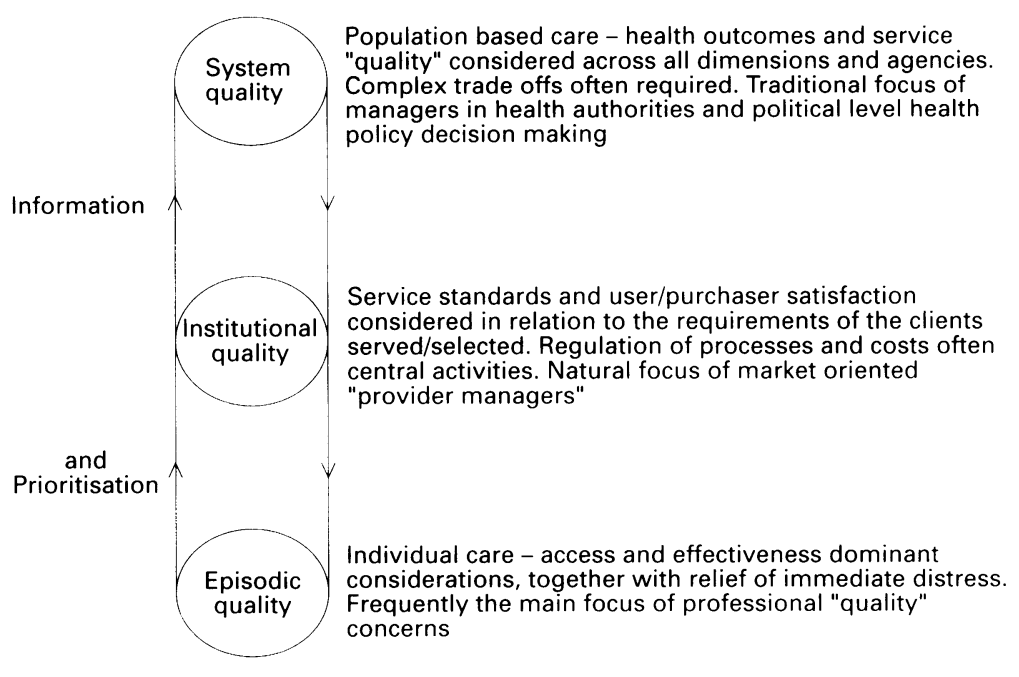

Figure 2 Levels of health care quality processes and outcomes can in any case be very hard to discriminate. Caring well for a dying person, for instance, may be thought of as an end in itself rather than an act or series of acts intended to change a subsequent result. The conclusion is that the management of process must be at the heart of work on service quality, albeit that if purchasers have reliable outcome information they may choose to avoid becoming too closely involved in the internal affairs of provider organisations. Within such organisations staff seeking improvement need to establish firmly the precise relation between health care structure and process and the achievement of desired ends.

\section{Progress of quality improvement in the NHS}

The commission's research indicates that among management staff and at least a proportion of the clinical NHS workforce there has been considerable success since 1989-90 in transmitting and learning concepts of quality management. Some examples of the ideas that people in the health service readily associate with quality are given in the box.

\section{Ideas associated with quality}

Right thing, right time, right first time

Conformance to customer requirements - giving them (patients) what they want

Not having to say sorry - being proud you work here

Setting standards and delivering them

Making this (hospital) their world, the patients' world, not keeping turned in to ourselves any more

However there is so far little firm evidence of returns in terms of better patient care being generated as a result of the several hundred million pounds spent in England and Wales alone on professional audit and other quality initiatives in the past five years. Publications such as the $A-Z$ of Quality $^{9}$ indicate that gains have been achieved; but in the long term both economists and quality managers are going to have to assure themselves that these gains outweigh the benefits which would have accured from alternative investments in health or social care.

Critics of the NHS quality improvement strategies adopted have suggested that they lack adequate intellectual grounding and coherence. At worst the strategies are said to have been characterised by "initiativitis," with fairly arbitrarily determined amounts of money being allocated to short term goals as opposed to resources being directed to well worked out plans for long term health gain. Yet the commission's conclusion is that considerable opportunities now exist for stepwise integration of the initially fragmented quality programmes established in the NHS since the publication of Working for Patients. ${ }^{2}$ Alongside developments like, for example, the establishment of the Cochrane Centre, the work of the National Casemix Office, and the publication of epidemiologically based needs assessments and the Effectiveness Bulletins, efforts to promote clinical audit ${ }^{10}$ and organisation wide approaches to quality throughout the NHS ${ }^{11}$ deserve due recognition. They offer the prospect of sustained future progress. Nevertheless, the commission's recent research in quality management in the NHS highlights some concerns, as follows.

- The extent of chief executive and senior management understanding of and commitment to quality management approaches

- The degree to which the values and vision underlying recent reforms have been communicated to staff and service users

- Lack of investment in training in quality management techniques

- The organisation of quality related support functions, and the need to avoid quality management becoming a low priority fringe activity rather than an integral part of all managerial and clinical activity

- Uncertainty of the value of accreditation systems, risk management techniques, and professional audit programmes

- Lack of appropriate mechanisms for facilitating the expression of and giving due weight to service users' requirements, and for communicating with patients and potential patients about service changes

- The ability of both authority and practice purchasing to influence positively service standards or quality

- The lack of knowledge of the cost of (poor) quality data in the NHS, and the need to link more closely the use of quality management techniques with health economics and other forms of social scientific evaluation.

\section{Ways forward}

There can be no miracle treatment to ensure the quality of the health service. As indicated above, the effective pursuit of better standards will require constant effort across a very wide range of areas, involving all staff working at all levels. The need to involve clinicians closely in (quality) management and to overcome counterproductive barriers to joint working between different groups of professionals 
highlights the type of cultural change the health service must now strive to achieve. At the same time, of course, the NHS is also having to accommodate ongoing structural changes, the most recent demanding a refocusing of central and regional functions towards market regulation, while greater operational control and freedom is passed "down" to unified local care purchasers and the provider trusts and practices.

Such developments should permit the centre to concentrate more effort on tasks like clarifying the values and intellectual principles on which NHS (quality) management should be based, advancing national initiatives like the patient's charter in the most appropriate ways, and identifying reliable outcomes based efficiency and performance indicators (or process measures linked to outcome data).

Among health authorities and providers hospitals, community services, and primary care practices - effective organisation wide approaches to quality management will demand the following:

- That authority and board members demonstrate an informed and vigorous commitment to quality management throughout their organisations and accept their accountability for introducing a systematic approach to continuous service improvement. Purchasers may, depending on circumstances, need to assure themselves that providers have appropriate and effective management arrangements in place

- That health care commissioners establish comprehensive understanding of the care needs and service preferences of their local populations and can demonstrate publicly how decision making about use of local NHS resources is consistent with "customer" requirements. This may require significant investments in local consumer representation and information services

- That in NHS trusts, quality support functions (audit coordination, quality assurance, risk management specialists, surveys, health services research, etc) be integrated efficiently to enable all line managers and clinicians to make continuous service improvement a central part of their everyday job

- That practice population based information about all forms of care access and other quality related service dimensions be made available and used as a central method of evaluating care delivery. All localities should be able to facilitate the development of the primary care competencies needed for professionally informed patient choice expressed at the practice level to become a key "driver" of service improvement.

The main contribution of the Audit Commission to the practical achievments of health care professionals and managerial staff in the NHS will continue in the context of the mainstream VFM and regularity audits.
However, the unique body of skills and experience the commission has built up in health care evaluation should be used to its maximum potential, not only for inspection or assurance but also as a developmental resource. One option in the process of appraisal relates to "commissioning for quality" and the particular challenges facing health authorities and GP fundholders seeking to raise service standards through this still evolving mechanism. Future initiatives might, for instance, include short-form audit guides designed to evaluate quality management functions, such as communicating with consumers and local community groups or purchasing clinical services for given client groups. These could help to integrate further disease management between all the NHS agencies and groups involved in care for given conditions.

\section{Conclusion}

For the NHS to use the resources available as well as possible and so to achieve the best quality of care for its users, those working in it need to understand patients' requirements and the effectiveness and costs of the treatments available to meet them. They must also be committed to working well with each other in striving to care for patients as well as they possibly can. Although the "old NHS" unquestionably enjoyed great public trust and staff loyalty, the care it was able to provide was not always of optimal quality.

A major test for the reformed health service will be not only to retain public confidence and healthy staff relations but also to improve on past achievements through the introduction of working methods which promote greater sensitivity to "customers" and more effective ways for the clinical professions to work together, and with other staff, to promote health gain. The introduction of improved quality management is thus a central task for everyone in today's NHS and one to which the Audit Commission will continue to contribute.

1 Davies H. Role of the Audit Commission. Quality in Health Care 1992;1(suppl):36-9.

2 Secretaries of State for Health, Wales, Northern Ireland, and Scotland. Working for patients. London: HMSO, 1989 (Cmnd 555.)

Maxwell R. Quality assessment in health. BMF 1984;288:1470-2.

4 Audit Commission. Minding the quality: the Audit Commission's role in promoting quality in the NHS. London: HMSO, 1992 .

5 Audit Commission. Putting quality on the map. London: HMSO, 1993. (Occasional paper No 18.)

6 Centre for Evaluation of Public Policy and Practice. Considering quality. Hillingdon: CEPPP, Brunel University, 1992.

7 Ovretveit J. Health service quality. London: Blackwell, 1992.

8 Pfeffer, Coote. Is quality good for you? London: Institute for Public Policy Research, 1991.

PS Management Executive. The $A-Z$ of quality. Leeds: NHSME, 1993.

10 Department of Health. Clinical audit. London: $\mathrm{DOH}$ 1993.

11 NHS Management Executive. Achieving an organisationwide approach to quality. Leeds: NHSME, 1993 (EL(93) 116. 